\title{
Obtenció de niló en un laboratori escolar
}

\author{
Dámaris Gancho IES Terrassa dgancho@pie.xtec.es
}

Es tracta d'obtenir un filament del polímer lineal PA66 també anomenat niló.

\section{FONAMENT TEÒRIC}

Els polímers de condensació es formen a partir de compostos amb grups funcionals actius, per reaccions químiques acompanyades de l'eliminació d'una molècula petita.

La policondensació és una reacció química a la qual intervenen dues molècules de reactius de naturalesa idèntica o diferent, però cadascuna, almenys amb dos grups funcionals. Va acompanyada de l'eliminació de productes secundaris senzills, de pes molecular petit, com l'aigua, el clorur d'hidrogen, etc.

Els polímers de condensació són el resultat de la reacció d'àcids carboxílics o derivats amb diols o diamines.

\section{Exemples de polímers de condensació}

\section{Naturals}

Cel.lulosa, midó, certes proteïnes (queratina que forma la llana i fibroïna que forma la seda) i el cautxú natural (amb el qual es forma el làtex que és una dispersió col·loidal de cautxú en aigua).

\section{Artificials}

Nilons y polièsters (elaboració de fibres tèxtils artificials), bakelita (polímer molt dur utilitzat per exemple per fer nanses de cafeteres), poliuretans (fabricació de fibres, escumes).
Quan fem el nylon la reacció que té lloc és:<smiles>[OH2+]C(Cl)CCCCCOOCl</smiles>

clorur d'adipoïl

$+\mathrm{H}_{2} \mathrm{~N}-\mathrm{CH}_{2}-\mathrm{CH}_{2}-\mathrm{CH}_{2}-\mathrm{CH}_{2}-\mathrm{CH}_{2}-\mathrm{CH}_{2}-\mathrm{NH}_{2} \rightarrow$ hexametilendiamina

$\rightarrow-\mathrm{CO}-\mathrm{CH}_{2}-\mathrm{CH}_{2}-\mathrm{CH}_{2}-\mathrm{CH}_{2}-\mathrm{CO}-\mathrm{HN}-\mathrm{CH}_{2}-$ $-\mathrm{CH}_{2}-\mathrm{CH}_{2}-\mathrm{CH}_{2}-\mathrm{CH}_{2}-\mathrm{CH}_{2}-\mathrm{NH}-+\mathrm{HCl}$ nylon 6,6

Material

- Vasos de precipitats petits $(50 \mathrm{~mL})$

- Proveta de $50 \mathrm{~mL}$

- Comptagotes

- Clip

- Vareta de vidre $(50 \mathrm{~cm})$

- Embut petit de vidre

\section{Reactius}

- Hexametilendiamina (C)

- Hidròxid d'amoni (amoníac) 2M (C, N)

- Clorur d'adipoïl (C)

- Ciclohexà (F)

\section{PROCEDIMENT}

Es farà a la vitrina ja que el ciclohexà fa pudor de gas.

1) Posar en un vas de precipitats petit $10 \mathrm{~mL}$ de dissolució aquosa de hexametilendiamina al 5\%

2) Afegir unes gotes d'hidròxid d'amoni $2 M$ Afegir lentament amb l'ajut d'un embut, $10 \mathrm{~mL}$ de clorur d'adipoïl en ciclohexà al $5 \%$. L'embut no ha de tocar mai la dissolució aquosa de hexametilendiamina. A la següent fotografia (fig. 1), es po- 
den apreciar les dues fases: a sota la dissolució de hexametilendiamina que és la fase aquosa i a sobre el clorur d'adipoïl que és la fase orgànica.

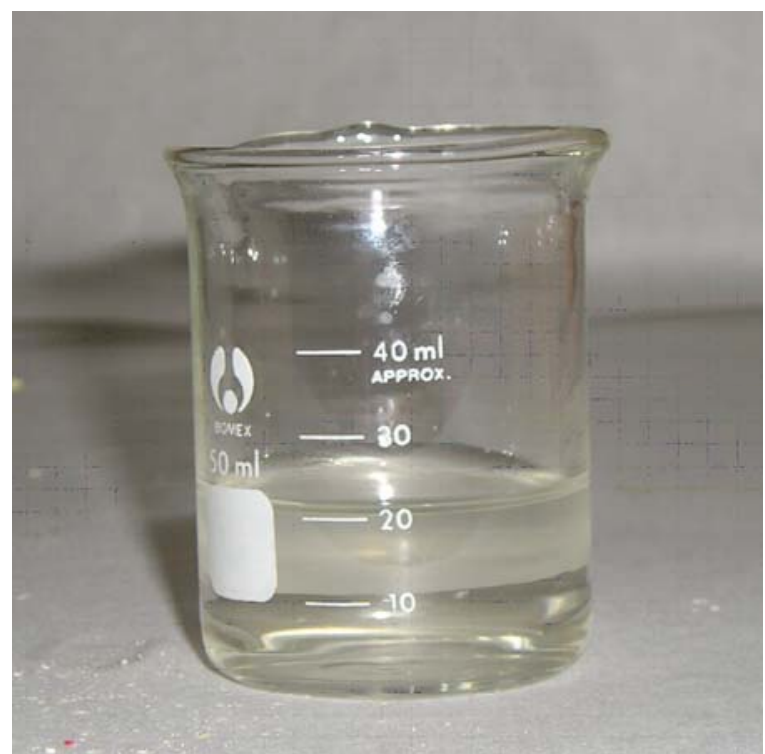

Figura 1. Fase aquosa, a sota, amb la fase orgànica al damunt.

1. Es formen dues capes i en la interfase una pel-lícula que correspon al polímer

2. Amb un filferro amb l'extrem doblegat /fig 2a), estirar aquesta pel-lícula (fig. 2b). El fil format es pot enrotllar en una vareta de vidre. Aquest fil és el niló que es podria trencar si s'estirés massa ràpidament.

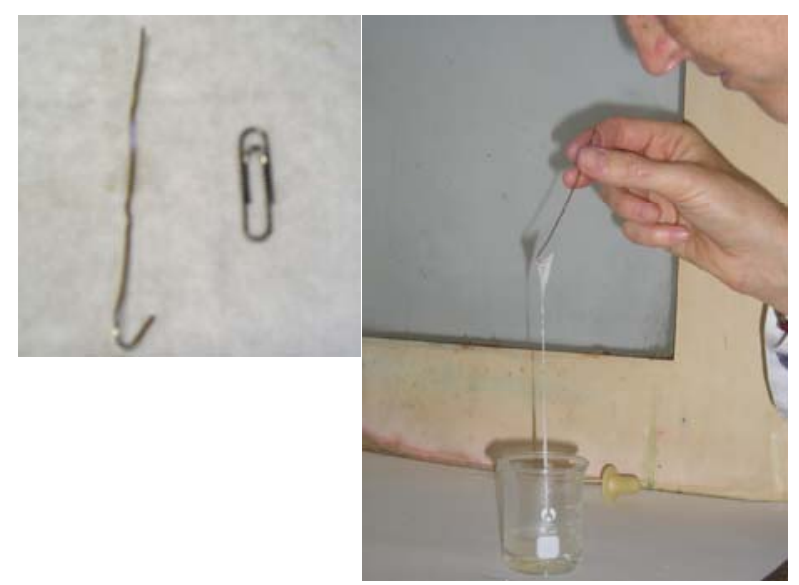

Figura 2. a) Clip deformat per servir de ganxo. b) Utilitzant-lo per obtenir el fil de niló.

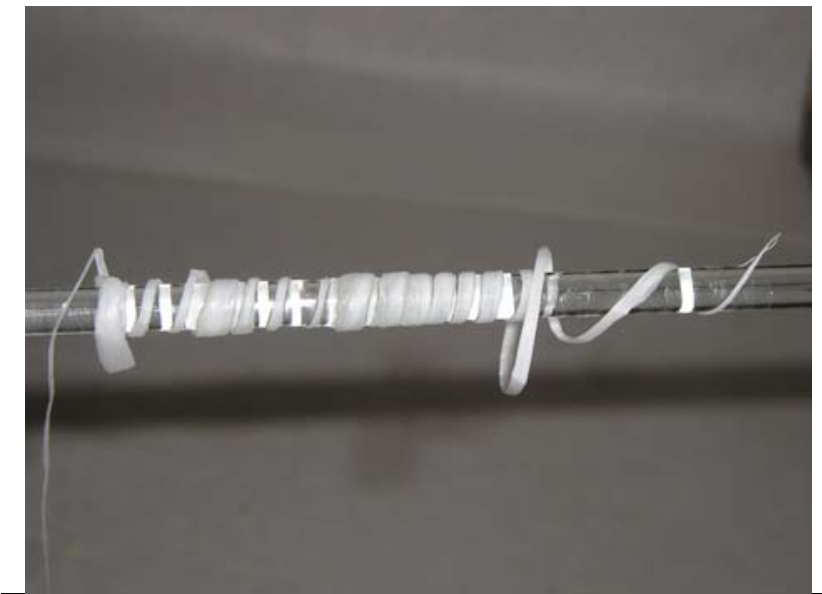

Figura 3. Enrotllant el "fil" mitjançant una vareta de vidre.

3. Amb els reactius que sobren es pot agitar enèrgicament i es formarà un residu de niló (fig. 4).

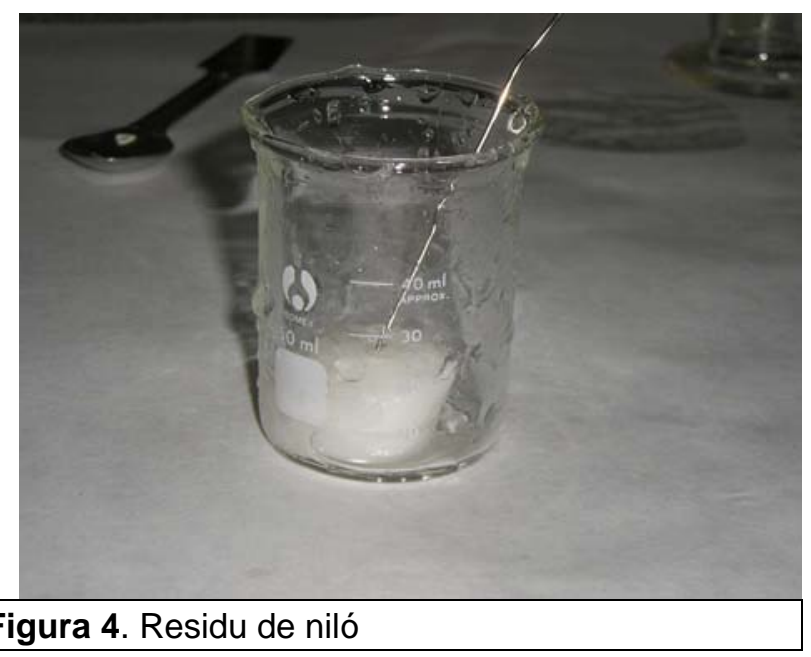

4. Rentar amb aigua el fil $i$ el residu de nylon $\mathrm{i}$ assecar-ho sobre un paper de filtre

\section{Qüestions:}

1. Posar una petita porció del residu de nylon en un tub d'assaig i agafant el tub amb unes pinces escalfar-lo suaument amb el bec Bunsen. Col.locar a la boca del tub una mica de paper indicador humit. Què passa?

2. Tallar una mica del nylon obtingut i posar-lo a la flama del bec Bunsen. Què passa?

3. Tallar uns quants trossos de nylon, introduir-los en un tub d'assaig, afegir $10 \mathrm{ml}$ 
d'àcid clorhídric al 10\% i escalfar. Què passa?

4. Quins grups funcionals intervenen a la reacció?

5. Explicar quin grup funcional s'ha format a la reacció

6. Descriure les propietats físiques del nylon obtingut

\section{BIBLIOGRAFIA}

Butruille,D. Rivas, J. Villarreal, F. (1982). Experimentos de química. Parte 2: Química orgánica y bioquímica. Ed TRILLAS

ANAIP, CEP. (1991) Los plàsticos: materiales de nuestro tiempo.

Paz, JJ. Soley, J. (2000) Crèdit 3: Assajos físics. CFGS Anàlisi i control. IES Terrassa.

Guarino, Cristina. Apunts de classe. IES Terrassa. 